\title{
Deconstructing Myc
}

\author{
Robert N. Eisenman ${ }^{1}$ \\ Division of Basic Sciences, Fred Hutchinson Cancer Research Center, Seattle, Washington 98109-1024, USA
}

\section{Background}

Although myc was among the very earliest oncogenes identified and the subject of intense study, it has nonetheless proven to be an enduring enigma. To a large extent the problem derives from the apparent gap between Myc's biological role and what is surmised to be its molecular function. Myc family proteins (comprising c-, N-, and L-Myc) promote proliferation, growth, and apoptosis; inhibit terminal differentiation; and, when deregulated, are profoundly involved in the genesis of an extraordinarily wide range of cancers (for recent review, see Grandori et al. 2000). Alongside this veritable mountain of biological effects, the molecular characterization of Myc_as a relatively weak transcriptional regulator of uncertain target genes-looks like a molehill. Indeed some have wondered whether the transcriptional activities of Myc might be more apparent than real.

The notion that Myc proteins might function in transcription arose over a decade ago, after Myc was shown to be a nuclear protein. An N-terminal fragment of Myc stimulated transcription when fused to a heterologous DNA binding domain, and the C-terminal basic-helixloop-helix-zipper (bHLHZ) of Myc resembled those found in certain families of transcription factors. But full-length Myc did not dimerize or bind DNA and therefore could not be demonstrated to behave as a transcription factor. This picture changed with the discovery of Max, another bHLHZ protein which heterodimerizes with Myc to form a sequence-specific DNA binding complex. Myc-Max heterodimers recognize the E-box sequence CACGTG (as well as related non-canonical sites) and activate transcription from synthetic reporter genes containing multimerized binding sites in mammalian cells as well as yeast (Blackwood and Eisenman 1991; Amati et al. 1992; Kretzner et al. 1992). The effects of Myc on cell proliferation and apoptosis are negated by mutations in the Myc transactivation region, or in the bHLHZ domain required for association with Max and DNA, indicating a tight linkage between the transcriptional and biological activities of Myc.

At first glance these findings would be expected to settle the issue of Myc function in favor of the idea that it is a transcription factor which, as a heterodimer with

${ }^{1}$ E-MAIL eisenman@fhcrc.org; FAX (206) 667-6522.

Article and publication are at http://www.genesdev.org/cgi/doi/10.1101/ gad928101.
Max, determines cell behavior by activation of a specific set of target genes. However, on second glance a number of complicating issues arise. First, Myc-Max transcriptional activity on either synthetic promoters or putative cellular target genes is disappointingly weak and variable (compared with other activators) - on the order of 2-5 fold. This makes detailed dissection of transcriptional function difficult and, even worse, makes validation of putative target genes both awkward and contentious (for review, see Grandori and Eisenman 1997). Second, although the transcriptional activity of Myc-Max was widely confirmed, there were also reports that Myc could repress transcription of a number of genes dependent on a specific subclass of initiator elements (INRs) located at the transcriptional initiation sites of certain genes (Li et al. 1994). Because the repression experiments did not demonstrate Myc binding to INRs, they left open the possibility that repression might be indirect (e.g. through activation of a repressor by Myc-Max). Third, mutational analyses of Myc Box II, a highly conserved region present in the $\mathrm{N}$-terminal transactivation region of all Myc proteins, produced confounding results. Several reports indicated that mutation of Myc Box II had little effect on transcription activation but abrogated Myc repression activity. Yet other studies indicated that loss of Myc Box II primarily affected activation. Because Myc Box II is crucial for the ability of Myc to transform cells, these results raised the issue of the relative importance of activation and repression (for review, see Grandori et al. 2000).

In principle, the importance of Myc transcriptional activity could be settled by identification of specific target genes. The hope was that Myc-Max might modulate expression of a small number of obviously critical genes whose known functions would explain the various biological effects of Myc. However, over the last eight years numerous putative target genes have been identified and, with the advent of global expression arrays, the number that are activated or repressed by Myc continues to grow. Whereas a few of these targets are cell cycle regulators, and therefore might help explain the ability of Myc to drive proliferation, many other candidate target genes have functions relating to metabolism, ribosome biogenesis, or translation, and do not immediately suggest a unitary mechanism for how Myc works. To make matters worse, there has been controversy over the validity of a number of the candidate target genes. For example, in a rat cell line in which $\mathrm{c}-m y c$ has been deleted, the 
introduction and activation of exogenous c-myc results in rescue of its slow proliferation phenotype (Mateyak et al. 1997). However, an analysis of Myc target genes in these cells indicated that only one of nine appeared dependent on Myc for activation (Bush et al. 1998). Given the relatively weak transcriptional activity of Myc, this and other studies raised the possibility that many presumed targets are either unimportant, incorrect, or indirect, and that activation of transcription by Myc may likewise be irrelevant (for review, see Cole and McMahon 1999).

Although the Myc morass seemed intractable, work from several different areas has recently converged to confirm and extend the notion that Myc, and other Max interacting proteins such as the Mad repressor (thought to be an antagonist of $\mathrm{Myc}$ ), function through modulation of target gene expression. First, both Myc and Mad have been found in complexes which possess histone modifying activities (for review, see Knoepfler and Eisenman 1999; Amati et al. 2001). Second, in two papers in this issue (Bouchard et al. 2001; Frank et al. 2001) the effects of Myc and Mad on the chromatin structure of a number of target genes are shown to be consistent with the functions of the transcription complexes which they recruit. In addition, other recent work has begun to reveal both the mechanism and importance of Myc repression (Seoane et al. 2001; Staller et al. 2001). Finally, a deeper understanding of the biology of Myc function has furnished a rationale for the role and number of $\mathrm{Myc}$ target genes.

\section{SINful TRRAPing and TIPing of transcriptional activities}

Delineating the underlying mechanism through which Myc and Mad modulate transcription would bolster the argument that their transcriptional activities are an intrinsic part of their function rather than secondary effects or assay artifacts. This was first shown for the Mad proteins which contain a clearly defined $\mathrm{N}$-terminal repression domain that associates directly with the highly conserved corepressor Sin3 (Ayer et al. 1995; SchreiberAgus et al. 1995; Brubaker et al. 2000). That Sin3 in turn binds the class I histone deacetylases HDAC1 and HDAC2 immediately suggests that Mad-Max recruits HDACs to its specific target DNA, presumably resulting in local deacetylation of histone tails within nucleosomes. Deacetylation of histones $\mathrm{H} 3$ and $\mathrm{H} 4$ has long been thought to promote transcriptional repression, possibly by augmenting internucleosomal and nucleosomeDNA association, and thereby decreasing the accessibility of DNA to positively acting factors (for reviews, see Kornberg and Lorch 1999; Grunstein 1997). The possibility that Mad-Max modifies chromatin structure, as a consequence of recruiting an HDAC, fits well with its repression activity and with the findings that Mad is expressed during terminal differentiation when silencing of proliferation related genes would be expected.

The other shoe dropped when Myc was found to associate with the coactivator TRRAP, a component of a large complex containing histone acetyltransferase (HAT) activity. TRRAP was purified as a $400 \mathrm{kD}$ protein associated with the controversial Myc Box II region of c-Myc, mentioned above (McMahon et al. 1998). TRRAP was also identified as a subunit common to several HATcontaining complexes including hGCN5/PCAF and Tip60/NuA4 (Vassilev et al. 1998; Ikura et al. 2000). A yeast TRRAP ortholog, Tralp, is a component of the yeast SAGA transcription complex which also possesses HAT activity as well as other factors that are thought to influence positioning of the basal transcription machinery (Saleh et al. 1998). Putative dominant negative mutants of TRRAP inhibit Myc transforming activity, indicating that interaction with TRRAP is important for at least this aspect of Myc biology. The implication that TRRAP binding to Myc results in HAT recruitment has recently been confirmed by coimmunoprecipitation experiments showing that endogenous Myc-Max heterodimers are associated with hGCN5 and HAT activity (McMahon et al. 2000).

Two other functions relating to chromatin-mediated transcriptional activity are associated with Myc. The TIP48/TIP49 proteins, which possess ATPase/helicase activities, are detected in association with the Myc Nterminal transactivation region, and a Tip49 mutation in its ATPase region dominantly interferes with Myc oncogenicity (Wood et al. 2000). As Tip48 and Tip49 require Myc Box II for interaction with Myc (Wood et al. 2000), and have also been found to be subunits of a TRRAPTip60 HAT complex (Ikura et al. 2000), it is plausible that TRAPP mediates binding of the TIP60 complex with Myc, although this remains to be examined in more detail. A third chromatin modifying activity reported to be associated with Myc is INI1 (Cheng et al. 1999), an ortholog of yeast SNF5, which is a subunit of the SWI/ SNF ATP-dependent chromatin remodeling complex (Wang et al. 1996).

\section{Myc and Mad mediate histone acetylation and deacetylation}

The association of Mad proteins with HDACs, and of Myc proteins with HATs, leads to the prediction that these histone modifying activities will be manifested at Mad and Myc binding sites in chromatin. This, of course, does not necessarily have to be the case as acetylation/ deacetylation may be directed to non-nucleosomal proteins and, in principle, could be independent of Myc and Mad association with DNA. Indeed, a recent study indicated that no augmentation of histone acetylation can be detected upon Myc binding to the promoters of the CAD and telomerase genes (Eberhardy et al. 2000). However the two papers in this issue make it evident that MycMax and Mad-Max binding to specific target genes is accompanied by histone acetylation and deacetylation (Bouchard et al. 2001; Frank et al. 2001). Both laboratories use the same overall approach to assess the association of Myc with specific DNA sequences and changes in local modification of histones. They employ formaldehyde to induce global cross-linking of proteins with 
DNA, and then fragment and immunoprecipitate the DNA-protein complexes with antibodies directed against components in the protein complexes (e.g., Myc, Mad, acetylated histones). The presence of specific DNA sequences coprecipitated with the protein complexes is then assessed by PCR using primer sets covering the sequences of interest (e.g., target gene promoters). This type of chromatin immunoprecipitation (ChIP) assay has come into wide use and, for example, was earlier employed to demonstrate that Myc associates with E-box sites in the promoter of the cad and odc genes (Boyd and Farnham 1997, 1999). The ChIP provides a means of assaying the association of cellular proteins with chromatin. However, it is limited by the specificity of the antibodies and the possibility of artifactual interactions due to the use of cross-linker.

In aggregate, the two new studies in this issue analyze ten putative Myc-Max target genes. Several of these, such as odc, cyclin D2, and cad, are generally accepted as targets, whereas several others such as $\alpha$-prothymosin and $n m 23$ are controversial. Bouchard et al. (2001) focus on the cyclin D2 gene, while Frank et al. (2001) survey nine other target genes. In the ChIP assays, Myc is shown to bind specifically within E-box-containing regions in all of these target genes. Thus endogenous cMyc is observed to progressively associate, as a function of time, with target E-boxes in response to serum treatment in a rat fibroblast cell line, but not in cognate cells harboring a c-myc deletion. As expected for an immediate early response gene such as $\mathrm{c}-\mathrm{myc}$, binding of the c-Myc protein to target E-boxes is rapid, occurring between 30-60 min after serum treatment, reaches a maximum at $4 \mathrm{~h}$ and then declines. Expression of an introduced Myc-estrogen receptor ligand-binding domain fusion protein (Myc-ER), which only interacts with Max in the presence of hydroxytamoxifen $(\mathrm{OHT})$, results in target gene binding following treatment with the ligand. Other genes not identified previously as targets do not show Myc binding to their promoter regions even though they may contain E-boxes. An impressive example of specificity is provided by the cyclin $D 2$ promoter which contains two canonical E-boxes, of which only the distal E-box associates with Myc in the assay.

The binding of these target gene E-boxes by Myc correlates well with increased acetylation of histone $\mathrm{H} 4$ as shown by ChIP. The time courses of c-Myc binding and $\mathrm{H} 4$ acetylation in response to serum are very similar, and cells lacking endogenous c-myc, as well as cells with inactive Myc-ER, fail to show the augmented acetylation. However, $\mathrm{H} 4$ acetylation at Myc binding sites is stimulated following introduction of wild-type c-myc into the c-myc null cells, or OHT treatment of Myc-ER expressing cells. The increased $\mathrm{H} 4$ acetylation is maximal at the Myc-binding sites and appears to extend in both directions, although definitive boundaries are difficult to establish because of the primer set spacing. For cyclin D2, $\mathrm{H} 4$ acetylation is apparent only for the distal, Myc-bound, E-box although both the proximal and distal E-boxes are apparently within nucleosomes. For all of the target genes, acetylation of histone $\mathrm{H} 3$ is initially relatively high even in quiescent cells, and no significant trend towards increased acetylation is observed after addition of serum. Therefore, although GCN5 and the TIP60 complexes are known to acetylate both $\mathrm{H} 3$ and $\mathrm{H} 4$, the activity associated with Myc is exhibited primarily through $\mathrm{H} 4$ modification.

If Myc is responsible for $\mathrm{H} 4$ acetylation by recruiting the TRRAP coactivator complex, then Myc mutants that do not interact with TRRAP should still bind E-boxes but not stimulate $\mathrm{H} 4$ acetylation. In fact, deletion of the Myc Box II region renders Myc unable to induce cyclin D2 or acetylate $\mathrm{H} 4$ at the distal E-box, although it still associates with this site. Likewise, a deletion in N-terminal Myc Box I, which is additionally required for TRRAP binding to Myc, also abrogates $\mathrm{H} 4$ acetylation near E-box binding sites. As expected, ChIP assays show the presence of TRRAP at Myc binding sites within the cyclin D2 and nucleolin promoters, but not at control non-target promoters. Unfortunately, neither study reports ChIP results with antisera against GCN5 and TIP proteins, leaving the exact composition of the coactivator complex unresolved.

How well does H4 acetylation correlate with induction of the target genes by Myc? Frank et al. (2001) show that eight of the genes found to bind Myc and acetylate $\mathrm{H} 4$ are induced efficiently in wild-type but not c-myc null Rat1 cells in response to serum. Introduction of c$m y c$ into the c- $\mathrm{myc}^{-/-}$cells effectively rescues the ability of these genes to respond to serum. Here, acetylation of H4 occurs prior to target gene expression. When Myc-ER is activated in wild-type Ratl cells in the absence of serum, the induction of many target genes is evident but is delayed and attenuated compared to Myc-ER activation in the presence of serum. This suggests that Myc alone can induce target gene expression but is not able to fully account for the transcription response to mitogenesis.

The results of these expression studies are quite different from an earlier report using the same Rat $1 \mathrm{myc}^{-/-}$ cell line (Bush et al. 1998), where, as mentioned above, only cad was found to be Myc-responsive. Frank et al. (2001) point out that the gapdh reference gene, used to normalize gene expression levels in the previous work, is itself responsive to serum as well as Myc, and may have obscured the induction of the target genes tested in the earlier work. Another point concerns the report of a lack of acetylation at the cad promoter (Eberhardy et al. 2000). Although Frank et al. (2001) argue that the discrepancy may be due to technical aspects of the ChIP assay, this issue remains to be settled. Nonetheless, the sheer weight of the present data indicate that in several different settings a Max-Myc-TRRAP coactivator complex can be shown to bind specific E-boxes, generate acetylation of $\mathrm{H} 4$ in the vicinity of the binding site, and stimulate at least a partial induction of target gene expression (Fig. 1).

Bouchard et al. (2001) take this idea one step further by showing that $\mathrm{H} 4$ deacetylation through Mad-Max complexes accompanies repression of the cyclin D2 target gene during terminal differentiation. They use the HL60 

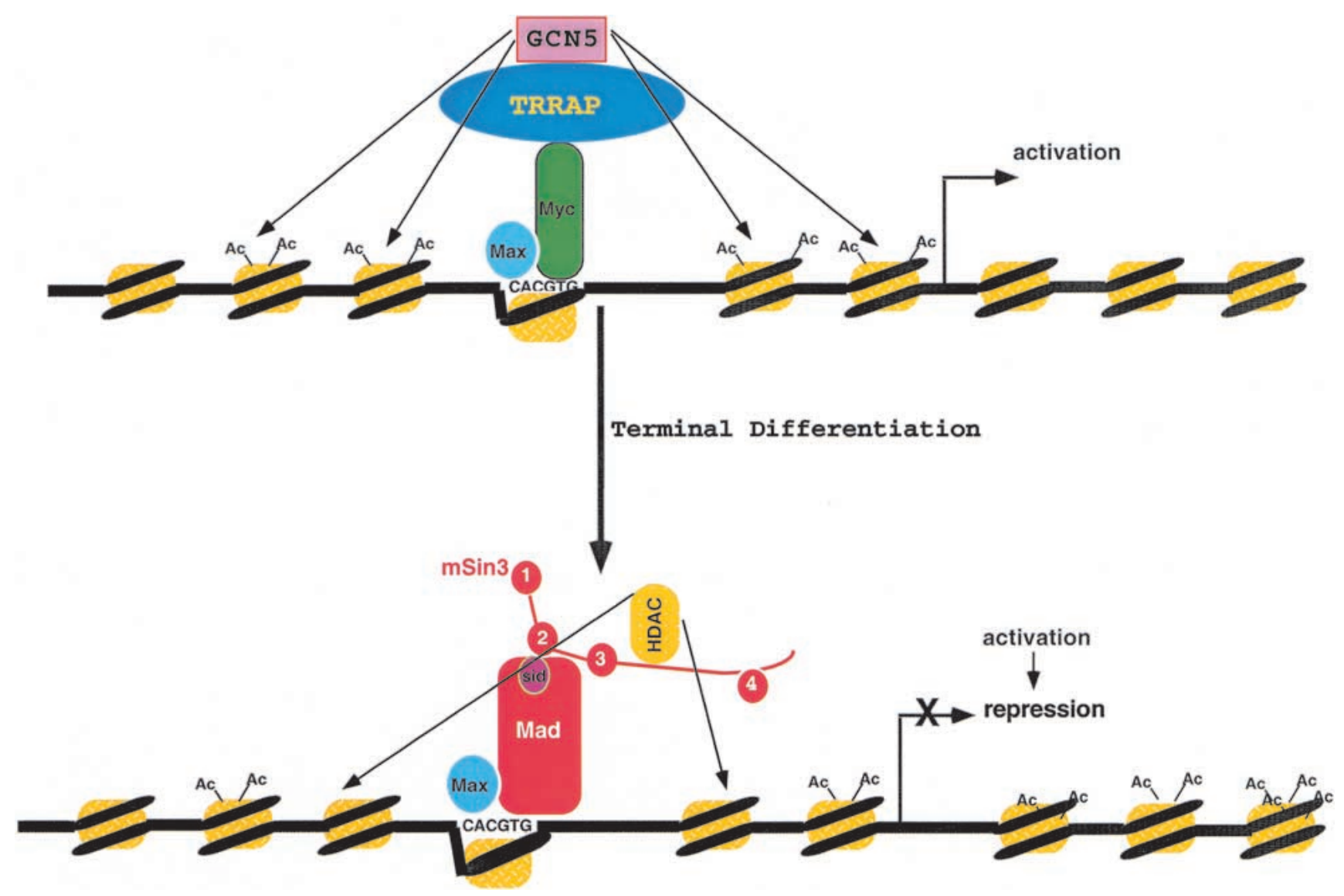

Figure 1. Myc and Mad regulate the acetylation state of nucleosomal histones near E-box binding sites. The upper portion of the figure depicts a Myc-Max heterodimer bound to an E-box sequence (CACGTG) near the promoter of a target gene. The Myc Box II domain mediates recruitment of the TRRAP coactivator and the HAT, GCN5. GCN5 acetylates nucleosomal histones at the E-box and adjacent regions. The augmented acetylation is part of a pathway resulting in expression of the target gene. The lower portion of the figure depicts the consequences of Myc down-regulation and Mad induction during terminal differentiation. Now Mad-Max heterodimers occupy the target gene E-box site. Mad recruits the mSin3 corepressor and HDACs leading to deacetylation and repression of target gene expression (numbers indicate interaction domains within $\mathrm{mSin} 3$ ). The boundaries of acetylation/deacetylation have not been sharply defined. See text for details.

cell line, which undergoes macrophage differentiation following treatment with the phorbolester TPA, and show that TPA treatment results in a switch from MycMax to Mad1-Max association with the E-box-containing region of the cyclin D2 promoter. Myc-Max to MadMax complex switching, which occurs during terminal differentiation, had been shown earlier in hematopoietic and epidermal cells (Ayer and Eisenman 1993; Hurlin et al. 1995). However, the new work shows that the MadMax heterocomplexes not only bind target gene DNA, but binding correlates with a decrease in the level of acetylation of $\mathrm{H} 3$ and $\mathrm{H} 4$ in the cyclin $\mathrm{D} 2$ promoter region. The deacetylation precedes the shut-off of cyclin $D 2$ and correlates with increased binding of HDAC1, and decreased association of RNA polymerase II, with the E-box region. These findings are consistent with another recent report indicating that Mad binding results in deacetylation of the human Tert promoter during terminal differentiation (Xu et al. 2001). Thus, Myc-Max to Mad-Max heterodimer switching during differentiation results in a dynamic change in histone acetylation status (Fig. 1).

The data presented in the two papers raise interesting issues relating to the dynamics of complex formation and DNA interaction. Frank et al. (2001) show that only on the order of $0.1 \%-1 \%$ of total target gene sequences can be detected in a complex with Myc as determined by real-time PCR assay. This may result from an intrinsic inefficiency of the immunoprecipitation assays, but it may also relate to the possibility that the short-lived c-Myc protein may not exist in continuous long-term association with the E-box. In fact, a previous study had suggested that Myc and the USF transcription factor may bind E-boxes in a stochastic manner (Boyd and Farnham 1999). Perhaps even transient occupation of the E-box by Myc is sufficient to induce stable acetylation, explaining why the levels of $\mathrm{H} 4$ acetylation at binding sites approaches $20 \%$. Perhaps the rapid turnover of Myc is intimately linked to recruitment of the basal transcription apparatus as shown recently for yeast Gen4 (Chi et al. 
2001). Interestingly, stabilization of the Myc protein has been shown to correlate with Ras pathway-mediated phosphorylation (Sears et al. 2000) as well as certain mutations found in a subset of neoplasms (Salghetti et al. 1999; but see Chang et al. 2000). A relatively stabilized Myc might well change the dynamics of acetylation and gene activation. Nonetheless, following a peak of acetylation at $4 \mathrm{~h}$ after serum induction, the levels of acetylation on most target promoters show a marked decrease (Frank et al. 2001, see Fig. 4A) suggesting that a deacetylase may also be active in the vicinity. This is consistent with the increased acetylation at the cyclin D2 E-box region following treatment with TSA, an HDAC inhibitor (Bouchard et al. 2001, see Fig. 3C). In this regard it is interesting that $\mathrm{Mnt}$, another Max binding repressor that associates with $\mathrm{mSin} 3$, is coexpressed with Myc throughout development (in contrast to Mad1, which is induced only during differentiation when Myc is down-regulated; Hurlin et al. 1997; Sommer et al. 1998). Perhaps Myc is functioning as a transient anti-repressor to counteract a basal level of histone deacetylation and thereby facilitate the action of other transcription factors by opening up specific segments of chromatin. This may explain the relatively wimpy transcriptional activity of Myc on its own.

Another issue concerns the rather lopsided acetylation, of just $\mathrm{H} 4$ rather than both $\mathrm{H} 4$ and $\mathrm{H} 3$, following Myc-Max binding that is observed in both papers. One explanation could be that the antibody used for the acetylated-H3 ChIP does not recognize all acetylated lysines. Alternatively, a lack of increased H3 acetylation may be due to the specific composition and activities of the coactivator complex, which has not been fully elucidated in these studies. Again, this may relate to the notion that Myc alone cannot achieve full activation or target genes. The concept of a "histone code" (Strahl and Allis 2000) suggests that specific patterns of histone modification may provoke binding by distinct sets of transcription factors and chromatin modifying activities. Perhaps Myc-TRRAP specifies only a portion of the code with other factors or coactivator complexes furnishing the rest in response to serum induction or other cellular stimuli. There is also ample evidence that transcriptional activation requires coupling of chromatin remodeling with histone acetylation (Fry and Workman 2001; Hassan et al. 2001), suggesting that Myc-Max either supplies its own remodeling activity, perhaps in the form of INI1, or will be found to function in concert with other chromatin remodeling complexes. Studies on the yeast $\mathrm{HO}, \mathrm{MMTV}$, and interferon $\beta$ promoters provide strong precedents for ordered binding of distinct factors and activites (Cosma et al. 1999; Agalioti et al. 2000; Fletcher et al. 2000).

\section{Myc repression: getting a grip on activators}

Repression mediated by Myc is a particularly murky area because it has not been compellingly linked to a specific DNA-binding activity of Myc. Furthermore, Myc does not appear to associate with repressors or corepressors.
Several recently published papers now provide support for the idea that Myc repression results, not from direct binding to DNA by Myc-Max, but rather from their interaction with positively acting transcription factors (Gartel et al. 2001; Seoane et al. 2001; Staller et al. 2001; for review, see Orian and Eisenman 2001). Several years ago the $\mathrm{Zn}^{2+}$ finger/POZ domain protein, Miz-1, was found to interact with the bHLHZ region of Myc (Peukert et al. 1997). More recently, Staller et al. (2001) report that Miz-1 overexpression leads to cell cycle arrest and specific induction of the $p 15^{I N K 4 B}$ cyclin dependent kinase inhibitor (CDKI) through binding to the $p 15^{I N K 4 B}$ Inr. They go on to show that Myc blocks the ability of Miz-1 to induce $p 15^{I N K 4 B}$ by interacting directly with Miz-1. Surprisingly Myc does not simply sequester Miz-1 but instead, together with Max, is recruited to the $p 15^{I N K 4 B}$ Inr. The interaction of Myc-Max with Miz-1 appears to block association of Miz-1 with its own coactivator, the HAT-containing P300 protein. Why MycMax fails to activate thorough TRRAP is unclear at this point. Perhaps TRRAP is excluded from the Miz-MycMax complex or perhaps TRRAP is unable to activate transcription in the context of an Inr. Whatever the reason, $p 15^{I N K 4 B}$ expression is not induced in the presence of Myc. As shown by Seoane et al. (2001), TGF $\beta$ treatment, which has been long known to result in downregulation of Myc, releases Miz-1 from the inhibitory complex. Together with Sp1 and Smad binding to upstream elements, the Miz-1-P300 complex at the Inr activates $p 15^{I N K 4 B}$ expression, thereby promoting cell cycle arrest. Similarly, down-regulation of another CDKI, p21 ${ }^{\mathrm{CIP} 1}$, by Myc has also been reported to involve its binding to the Spl transcription factor (Gartel et al. 2001).

Interestingly, many of the genes reported to be downregulated by Myc, like $p 15^{I N K 4 B}$ and $p 21^{C I P 1}$, are thought to be involved in proliferation arrest. It remains to be seen how many of these are repressed through Myc's subversion of specific transcriptional activators. Other mechanisms of Myc repression are certainly possible. Nonetheless, the Miz-1 findings provide a mechanism that explains the early observation that Myc represses through specific Inrs (Li et al. 1994).

\section{An avalanche of targets}

The new findings on the mechanisms underlying Myc activation and repression should serve to concentrate our attention on the number and nature of Myc target genes as the primary means of understanding the complex biology of Myc and other factors associated with the Max network. However, the focus on targets presents a different set of problems-how to evaluate the flood of putative targets arising from global gene expression analyses and how to determine the relative importance of any individual target. Because many cells undergo profound changes in their behavior following up-regulation of Myc, special conditions are required to distinguish "direct" gene targets of Myc (defined as those genes which Myc binds to and influences the expression of) 
from "indirect" effects. At least one important repercussion of the new work should be a ratcheting up of the standards so that ChIP assays for Myc binding and acetylation will now be required for target gene validation. Certainly, one approach to dealing with the plethora of putative target genes is to attempt to discern broader patterns of altered gene expression that may relate to new pathways through which Myc functions biologically.

Some broader patterns of Myc-regulated gene expression are quite apparent. As mentioned earlier, many of the genes repressed by Myc are those which function in arrest of proliferation, including $p 15^{\text {Ink } 4 B}, p 21^{\text {Cip1 } 1}$, gadd45, and gas1. In addition, some genes activated by Myc may serve to limit the function of arrest genes. Thus, Myc induction of Cyclin D2 and the ubiquitin ligase component Cul1 have both been shown to subvert p2 $7^{\text {Kip } 1}$, thereby stimulating cyclin E-dependent kinase activity. Myc has also been shown to increase transcription of cell cycle regulatory genes such as those encoding Cdk4, cyclin D1, cyclin D2, cyclin A, cyclin E, cdc25A, p19 arf, and Id2. Of these, cdk4, cyclin D2, Id2, and cdc25A are considered direct targets (for review, see Amati et al. 1998). If these gene products are rate-limiting for cell cycle progression then the modest increases induced by Myc could help drive proliferation and account for other aspects of Myc function such as apoptosis. For example, the induction of $19^{\text {arf }}$ by Myc, although unlikely to be direct, has been shown to be important in p53-dependent apoptosis. Inactivation of the p19 ${ }^{\text {arf }}-M d m 2-p 53$ pathway inhibits apoptosis and plays a crucial role in acceleration of Myc-induced B-cell lymphomagenesis in mice (Eischen et al. 1999).

By far, most Myc target genes had been relegated to the seemingly mundane category of growth and metabolism and received relatively little attention. Nonetheless, it was suggested earlier that a potentially important function for Myc might be to regulate the rate of growth (defined as an increase in cell mass and size) that is thought to be required for cell cycle progression and cell division (Neufeld and Edgar 1998; Schmidt 1999). Indeed, a series of recent studies have reinforced the notion that growth regulation is likely to be an important function of Myc that is separable from its other biological effects. Genetic analysis of a Drosophila myc ortholog (dmyc) has shown that $\mathrm{dmyc}$ function is required to maintain the normal size of cells and organs. In contrast, dmyc overexpression produces larger cells. Neither dmyc loss of function nor overexpression have a significant effect on cell division rate, suggesting that the effects of Myc on growth are distinct from its effects on cell division (Johnston et al. 1999). These findings have been extended to mammalian cells. For example, in primary B cells, c-Myc overexpression produces larger cells at every stage of development (Iritani and Eisenman 1999). In a B cell line, as well as in fibroblasts, Myc has been shown to augment growth, independent of its effects on cell cycle (Schuhmacher et al. 1999; Beier et al. 2000). The growth studies are in accord with recent data from several global gene expression analyses in which a majority of genes, up-regulated following Myc induction in a variety of contexts, are seen to be involved in ribosome biogenesis, energy and nucleotide metabolism, and translational regulation (Coller et al. 2000; Guo et al. 2000; Boon et al. 2001; Schuhmacher et al. 2001). Whereas many of these may be due to secondary effects of Myc, their identification reinforces the view that the capacity of Myc to drive cell cycle progression is due, in part, to its stimulation of growth.

\section{Converting outside signals to gene expression programs}

A striking aspect of c-myc regulation is its rapid induction in response to many different types of mitogenic stimuli. Where examined, myc induction has been shown to be primarily an immediate early type response, not requiring intervening gene expression or protein synthesis. Few of the pathways regulating c-myc expression have been fully elucidated and the c-myc promoter remains something of a black box. Signaling through the Src kinase has been implicated in c-myc induction (Barone and Courtneidge 1995) and recently this idea has received support from experiments showing that Src, through a Rac-dependent pathway, mediates PDGFR signaling to c-myc (Chiariello et al. 2001). Expression of the $c-m y c$ gene may also be under the general control of $\mathrm{FKB}$, a KH domain protein that binds an element $1.5 \mathrm{~kb}$ upstream of the c-myc promoter (He et al. 2000). At another level, Ras and the AKT/GSKIII pathways appear to regulate Myc protein stability (Sears et al. 2000). Apparently many growth factor and cytokine signaling pathways converge to regulate the abundance of c-Myc protein.

Considered together, the response of myc (and mad) genes to a wide range of signaling pathways, and the emerging roles of Myc and Mad proteins as transcriptional regulators, support a view of Myc, and the Max network in general, as a functional module that integrates external signals in order to mediate specific programs of gene expression. As mentioned above, these gene expression programs plausibly relate to cell cycle progression and cell growth. They are also likely to affect cell life-span, apoptosis, morphology, and DNA integrity. A major unresolved question is how Myc promotes tumorigenesis. Is it simply by sharply increased and unrelieved activation/repression of its normal target genes, or are new target genes incorporated into its transcriptional sphere as Myc is inappropriately overexpressed? The unveiling of Myc's mechanism of target gene regulation through modification of chromatin structure, and the identification of critical target genes, will soon probably lead to answers to this question and also provide a basis for strategies to selectively inhibit Myc function in cancer cells. In the final analysis, Myc emerges as a transcription factor that is perhaps not fundamentally different from many other transcription factors. What will continue to make Myc unique and intriguing is its regulation, the nature of its target genes, and its role within the Max transcription factor network. 


\section{Acknowledgments}

I am grateful to Mark Groudine, Amir Orian, and Shaun Cowley for their comments on this manuscript and to the Eisenman lab for continuing discussions on Myc. I apologize to those whose papers were not cited due to space limitations. Work mentioned here that was carried out in my laboratory was supported by grants from the National Cancer Institute-NIH and a Research Professorship from the American Cancer Society.

\section{References}

Agalioti, T., Lomvardas, S., Parekh, B., Yie, J., Maniatis, T., and Thanos, D. 2000. Ordered recruitment of chromatin modifying and general transcription factors to the IFN $\beta$ promoter. Cell 103: 667-678.

Amati, B., Dalton, S., Brooks, M.W., Littlewood, T.D., Evan, G.I., and Land, H. 1992. Transcriptional activation by the human c-Myc oncoprotein in yeast requires interaction with Max. Nature 359: 423-426.

Amati, B., Alevizopoulos, K., and Vlach, J. 1998. Myc and the cell cycle. Front. Bioscience 3: 250-268.

Amati, B., Frank, S.R., Donjerkovic, D., and Taubert, S. 2001. Function of the c-Myc oncoprotein in chromatin remodeling and transcription. Biochim. Biophys. Acta 1471: M135M145.

Ayer, D.E. and Eisenman, R.N. 1993. A switch from Myc:Max to Mad:Max heterocomplexes accompanies monocyte/macrophage differentiation. Genes \& Dev. 7: 2110-2119.

Ayer, D.E., Lawrence, Q.A., and Eisenman, R.N. 1995. MadMax transcriptional repression is mediated by ternary complex formation with mammalian homologs of yeast repressor Sin3 . Cell 80: 767-776.

Barone, M.V. and Courtneidge, S. 1995. Myc but not Fos rescue of a PDGF signalling block by kinase-inactive Src. Nature 378: 509-512.

Beier, R., Burgin, A., Kiermaier, A., Fero, M., Karsunky, H., Saffrich, R., Moroy, T., Ansorge, W., Roberts, J., and Eilers, M. 2000. Induction of cyclin E-cdk2 kinase activity, E2F-dependent transcription and cell growth by Myc are genetically separable events. EMBO I. 19: 5813-5823.

Blackwood, E.M. and Eisenman, R.N. 1991. Max: A helix-loophelix zipper protein that forms a sequence-specific DNA binding complex with Myc. Science 251: 1211-1217.

Boon, K., Caron, H.N., van Asperen, R., Valentijn, L., Hermus, M.-C., van Sluis, P., Roobeek, I., Weis, I., Voute, P.A., Schwab, M., et al. 2001. N-myc enhances the expression of a large set of genes functioning in ribosome biogenesis and protein synthesis. EMBO J. 20: 1383-1393.

Bouchard, C., Dittrich, O., Kiermaier, A., Dohmann, K., Menkel, A., Eilers, M., and Luscher, B. 2001. Regulation of cyclin D2 gene expression by the Myc/Max/Mad network: Mycdependent TRRAP recruitment and histone acetylation at the cyclin D2 promoter. Genes \& Dev. 15: 2042-2047 (this issue).

Boyd, K. and Farnham, P.J. 1997. Myc versus USF: Discrimination at the cad gene is determined by core promoter elements. Mol. Cell. Biol. 17: 2529-2537.

- 1999. Coexamination of site-specific transcription factor binding and promoter activity in living cells. Mol. Cell. Biol. 19: 8393-8399.

Brubaker, K., Cowley, S.M., Huang, K., Loo, L., Yochum, G.S., Ayer, D.E., Eisenman, R.N. and Radhakrishnan, I. 2000. Solution structure of the interacting domains of the Mad-Sin3 complex: Implications for recruitment of a chromatin-modifying complex. Cell 103: 655-665.
Bush, A., Mateyak, M., Dugan, K., Obaya, A., Adachi, S., Sedivy, J., and Cole, M. 1998. c-myc null cells misregulate cad and gadd45 but not other proposed c-Myc targets. Genes \& Dev. 12: 3797-3802.

Chang, D.W., Claasen, G.F., Hann, S.R., and Cole, M.D. 2000. The c-Myc transactivation domain is a direct modulator of apoptotic versus proliferative signals. Mol. Cell. Biol. 20: 4309-4319.

Cheng, S.-W.G., Davies, K.P., Yung, E., Beltran, R.J., Yu, J., and Kalpana, G.V. 1999. c-MYC interacts with INI1/hSNF5 and requires the SWI/SNF complex for activation function. Nat. Genet. 22: 102-105.

Chi, Y., Huddleston, M.J., Zhang, X., Young, R.A., Annan, R.S., Carr, S.A., and Deshaies, R.J. 2001. Negative regulation of Gen 4 and Msn2 transcription factors by Srb10 cyclin-dependent kinase. Genes \& Dev. 15: 1078-1092.

Chiariello, M., Marinissen, M.J., and Gutkind, J.S. 2001. Regulation of c-myc expression by PDGF through Rho GTPases. Nat. Cell Biol. 3: 580-586.

Cole, M.D. and McMahon, S.B. 1999. The Myc oncoprotein: A critical evaluation of transactivation and target gene regulation. Oncogene 18: 2916-2924.

Coller, H.A., Grandori, C., Tamayo, P., Colbert, T., Lander, E.S., Eisenman, R.N., and Golub, T.R. 2000. Expression analysis with oligonucleotide microarrays reveals Myc regulates genes involved in growth, cell cycle, signaling, and adhesion. Proc. Natl. Acad. Sci. 97: 3260-3265.

Cosma, M.P., Tanaka, T., and Nasmyth, K. 1999. Ordered recruitment of transcription and chromatin remodeling factors to a cell cycle- and developmentally regulated promoter. Cell 97: 299-311.

Eberhardy, S.R., D'Cunha, C.A., and Farnham, P.J. 2000. Direct examination of histone acetylation on Myc target genes using chromatin immunoprecipitation. J. Biol. Chem. 275: 33798-33805.

Eischen, C.M., Weber, J.D., Roussel, M.F., Sherr, C.J., and Cleveland, J.L. 1999. Disruption of the ARF-Mdm2-p53 tumor suppressor pathway in Myc-induced lymphomagenesis. Genes \& Dev. 13: 2658-2669.

Fletcher, T.M., Ryu, B.W., Baumann, C.T., Warren, B.S., Fragoso, G., John, S., and Hager, G.L. 2000. Structure and dynamic properties of a glucocorticoid receptor-induced chromatin transition. Mol. Cell. Biol. 20: 6466-6475.

Frank, S.R., Schroeder, M., Fernandez, P., Taubert, S., and Amati, B. 2001. Binding of c-Myc to chromatin mediates mitogen-induced actylation of histone $\mathrm{H} 4$ and gene activation. Genes \& Dev. 15: 2069-2082 (this issue).

Fry, C.J. and Workman, J.L. 2001. Chromatin remodeling enzymes: Who's on first? Curr. Bio. 11: R185-R197.

Gartel, A.L., Ye, X., Goufman, E., Shianov, P., Hay, N., Najmabadi, F., and Tyner, A.L. 2001. Myc represses the p21 (WAF1/CIP1) promoter and interacts with $\mathrm{Sp} 1 / \mathrm{Sp} 3$. Proc. Natl. Acad. Sci. 98: 4510-4515.

Grandori, C. and Eisenman, R.N. 1997. Myc target genes. Trends Biochem. Sci. 22: 177-181.

Grandori, C., Cowley, S.M., James, L.P., and Eisenman, R.N. 2000. The MYC/MAX/MAD network and the transcriptional control of cell behavior. Annu. Rev. Cell Dev. Biol. 16: 653-699.

Grunstein, M. 1997. Histone acetylation in chromatin structure and transcription. Nature 389: 349-352.

Guo, Q.M., Malek, R.L., Kim, S., Chiao, C., He, M., Ruffy, M., Sanka, K., Lee, N.H., Dang, C.V., and Liu, E.T. 2000. Identification of c-myc responsive genes using rat cDNA microarray. Cancer Res. 60: 5922-5928.

Hassan, A.H., Neely, K.E., and Workman, J.L. 2001. Histone 
acetyltransferase complexes stabilize SWI/SNF binding to promoter nucleosomes. Cell 104: 817-827.

He, L., Liu, J., Collins, I., Sanford, S., O'Connell, B., Benham, C.J., and Levens, D. 2000. Loss of FBP function arrests cellular proliferation and extinguishes c-myc expression. EMBO J. 19: 1034-1044.

Hurlin, P.J., Foley, K.P., Ayer, D.E., Eisenman, R.N., Hanahan, D., and Arbeit, J.M. 1995. Regulation of Myc and Mad during epidermal differentiation and HPV-associated tumorigenesis. Oncogene 11: 2487-2501.

Hurlin, P., Queva, C., and Eisenman, R.N. 1997. Mnt, a novel Max-interacting protein is coexpressed with Myc in proliferating cells and mediates repression at Myc binding sites. Genes \& Dev. 11: 44-58.

Ikura, T., Ogryzko, V.V., Grigoriev, M., Groisman, R., Wang, J., Horikoshi, M., Scully, R., Qin, J., and Nakatani, Y. 2000. Involvement of the TIP60 histone acetylase complex in DNA repair and apoptosis. Cell 102: 463-473.

Iritani, B.M. and Eisenman, Y. 1999. c-Myc enhances protein synthesis and cell size during B lymphocyte development. Proc. Natl. Acad. Sci. 96: 13180-13185.

Johnston, L.A., Prober, D.A., Edgar, B.A., Eisenman, R.N., and Gallant, P. 1999. Drosophila myc regulates growth during development. Cell 98: 779-790.

Knoepfler, P.S. and Eisenman, R.N. 1999. Sin meets NuRD and other tails of repression. Cell 99: 447-450.

Kornberg, R.D. and Lorch,Y. 1999. Twenty-five years of the nucleosome, fundamental particle of the eukaryotic chromosome. Cell 98: 285-294.

Kretzner, L., Blackwood, E.M., and Eisenman, R.N. 1992. The Myc and Max proteins possess distinct transcriptional activities. Nature 359: 426-429.

Li, L., Nerlov, K., Prendergast, G., MacGregor, D., and Ziff, E.B. 1994. c-Myc represses transcription in vivo by a novel mechanism dependent on the initiator element and Myc box II. EMBO J. 13: 4070-4079.

Mateyak, M.K., Obaya, A.J., Adachi, S., and Sedivy, J.M. 1997. Phenotypes of c-myc-deficient rat fibroblasts isolated by targeted homologous recombination. Cell Growth Diff. 8: 1039-1048.

McMahon, S.B., Van Buskirk, H.A., Dugan, K.A., Copeland, T.D., and Cole, M.D. 1998. The novel ATM-related protein TRRAP is an essential cofactor for the c-Myc and E2F oncoproteins. Cell 94: 363-374.

McMahon, S.B., Wood, M.A., and Cole, M.D. 2000. The essential cofactor TRRAP recruits the histone acetyltransferase hGCN5 to c-Myc. Mol. Cell. Biol. 20: 556-562.

Neufeld, T.P. and Edgar, B.A. 1998. Connections between growth and the cell cycle. Curr. Opin. Cell Biol. 10: 784790.

Orian, A. and Eisenman, R.N. 2001. TGF- $\beta$ flips the Myc switch. Science's STKE (http://stke.sciencemag.org/cgi/content/full/OC_sigtrans;2001/88/pe1).

Peukert, K., Staller, P., Schneider, A., Carmichael, G., Hanel, F., and Eilers, M. 1997. An alternative pathway for gene regulation by Myc. EMBO J. 16: 5672-5686.

Saleh, A., Schieltz, D., Ting, N., McMahon, S.B., Litchfield, D.W., Yates III, J.R., Lees-Miller, S.P., Cole, M.D., and Brandl, C.J. 1998. Tralp is a component of the yeast ada/spt transcriptional regulatory complexes. I. Biol. Chem 273: 26559-26565.

Salghetti, S.E., Kim, S.Y., and Tansey, W.P. 1999. Destruction of myc by ubiquitin-mediated proteolysis: Cancer-associated and transforming mutations stabilize myc. EMBO J. 18: $717-$ 726.

Schmidt, E.V. 1999. The role of c-myc in cellular growth con- trol. Oncogene 18: 2988-2996.

Schreiber-Agus, N., Chin, L., Chen, K., Torres, R., Rao, G., Guida, P., Skoultchi, A.I., and DePinho, R.A. 1995. An amino-terminal domain of Mxil mediates anti-Myc oncogenic activity and interacts with a homolog of the yeast repressor SIN3. Cell 80: 777-786.

Schuhmacher, M., Staege, M.S., Pajic, A., Polack, A., Weidle, U.H., Bornkamm, G.W., Eick, S., and Kohlhuber, F. 1999. Control of cell growth by c-Myc in the absence of cell division. Curr. Biol. 9: 1255-1258.

Schuhmacher, M., Kohlhuber, F., Holzel, M., Kaiser, C. Burtscher, H., Jarsch, M., Bornkamm, G.W., Laux, G., Polack, A., Weidle, U.H., et al. 2001. The transcriptional program of a human B cell line in response to myc. Nucleic Acids Res. 29: 397-406.

Sears, R., Nuckolls, F., Haura, E., Taya, Y., Tamai, K., and Nevins, J.R. 2000. Multiple ras-dependent phosphorylation pathways regulate myc protein stability. Genes \& Dev. 14: $2501-$ 2514.

Seoane, J., Pouponnot, C., Staller, P., Schader, M., Eilers, M., and Massague, J. 2001. TGF $\beta$ influences Myc, Miz-1 and Smad to control the CDK inhibitor p15 $5^{I N K 4 B}$. Nat. Cell Biol. 3: 400408.

Sommer, A., Bousset, K., Kremmer, E., Austen, M., and Luscher, B. 1998. Identification and characterization of specific DNAbinding complexes containing members of the myc/max/ mad network of transcriptional regulators. J. Biol. Chem. 273: 6632-6642.

Staller, P., Peukert, K., Kiermaier, A., Seoane, J., Lukas, J., Karsunky, H., Möröy, T., Bartek, J., Massague, J., Hänel, F., and Eilers, M. 2001. Repression of $p 15^{I N K 4 B}$ expression by Myc through association with Miz-1. Nat. Cell Biol. 3: 392399.

Strahl, B.D. and Allis, C.D. 2000. The language of covalent histone modifications. Nature 403: 41-45.

Vassilev, A., Yamauchi, J., Kotani, T., Prives, C., Avantaggiati, M.L., Qin, J., and Nakatani, Y. 1998. The $400 \mathrm{kda}$ subunit of the PCAF histone acetylase complex belongs to the ATM superfamily. Mol. Cell 2: 869-875.

Wang, W., Xue, Y., Zhou, S., Kuo, A., Cairns, B.R., and Crabtree, G.R. 1996. Diversity and specialization of mammalian SWI/ SNF complexes. Genes \& Dev. 10: 2117-2130.

Wood, M.A., McMahon, S.B., and Cole, M.D. 2000. An ATPase/ helicase complex is an essential cofactor for oncogenic transformation by c-Myc. Mol. Cell 5: 321-330.

Xu, D., Popov, N., Hou, M., Wang, Q., Bjorkholm, M., Gruber, A., Menkel, A.R., and Henriksson, M. 2001. Switch from Myc/Max to Mad1/Max binding and decrease in histone acetylation at the telomerase reverse transcriptase promoter during differentiation of HL60 cells. Proc. Natl. Acad. Sci. 98: 3826-3831. 


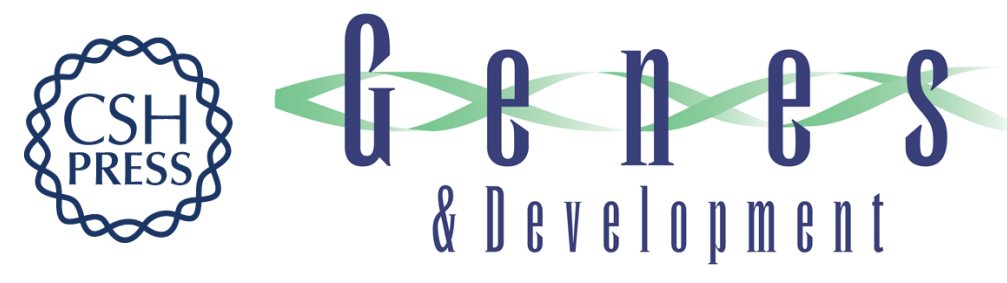

\section{Deconstructing Myc}

Robert N. Eisenman

Genes Dev. 2001, 15:

Access the most recent version at doi:10.1101/gad928101

References This article cites 63 articles, 29 of which can be accessed free at: http://genesdev.cshlp.org/content/15/16/2023.full.html\#ref-list-1

License

Email Alerting Receive free email alerts when new articles cite this article - sign up in the box at the top Service right corner of the article or click here.

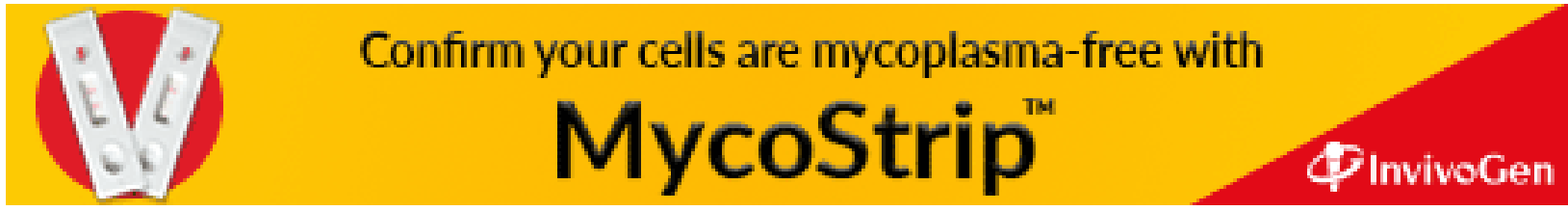

